carcinoma of the penis or prostate. Other recognizable traumatic and mechanical influences include putting a ring on the penis or the deliberate insertion of cartilage grafts in attempts to restore potency. Somewhat less obvious is the part played by certain blood diseases which predispose towards coagulation within the corpora cavernosa. Priapism, sometimes as a presenting feature in myeloid leukaemia, is now well known, and it has also been noted in cases of sicklecell anaemia.

Though there can be little doubt that the stimulus for physiological erection is conveyed via the nervi erigentes, the role of neurological diseases in causing priapism remains imperfectly understood. Recorded in criminals as a consequence of judicial hanging, and sometimes seen after injuries causing transection of the spinal cord, the condition may also complicate a variety of non-traumatic lesions such as those of neurosyphilis and non-specific myelitis. In such cases other indications of the underlying diseases are usually apparent.

There remain a group of cases in which no obvious exciting factor can be incriminated and to which the term primary (or idiopathic) priapism has been applied. They are of particular interest because of certain differences which they may show from normal physiological erection and also from priapism due to neurogenic causes. Whereas in neurogenic cases the whole organ becomes swollen and it can be assumed that both arterial dilatation and venous stasis play a part, in primary priapism the engorgement is mainly confined to the corpora cavernosa while the glans and corpus spongiosum drain well. This distinction is emphasized by W. J. Boerema ${ }^{1}$ in a study of a recent case and accords with the clinical observation that in such instances the ability to micturate is seldom impaired. He also points out that there is no evidence of proximal venous obstruction. Moreover, while the penis remains red and warm, aspiration of the deep dorsal vein (the main channel of return) reveals bright red blood yet fails to reduce the erection. ${ }^{2}$ Boerema concludes that primary priapism is the abnormal result of prolonged erection (thus possibly contravening the current definition), that it is mechanical in nature and not neurogenic, and that it is caused by impaired venous outflow confined to the corpora cavernosa. The outflow is thought to be impaired owing to increased viscosity of the blood, with subsequent inflammation of the septa compressing the venules. Consequently early and repeated aspiration to remove and prevent the further accumulation of altered blood is recommended and may appropriately be carried out by means of a fine nylon catheter, as Boerema describes.

The use of anticoagulants when the cause of the priapism is found to be thrombosis has also been favourably reported on. W. J. Fraser ${ }^{3}$ described the case of a 13-year-old boy in whom priapism followed an accidental kick in the perineum. Thrombosis-but not in the corpora cavernosa -was thought to be partly responsible for the condition, and recovery followed treatment with heparin and ethylbiscoumacetate. Two cases, adults in their 30 s, were later reported by J. Oldfield. ${ }^{4}$ In the first the priapism resolved after treatment with heparin alone and in the second only after forcible massage under general anaesthesia had been performed in addition to the administration of heparin. But D. M. Freeman ${ }^{5}$ has doubted whether anticoagulants really play the part that has been attributed to them, because a 53-year-old man in his care, on full anticoagulant treatment for cardiac infarction, developed primary priapism. It subsided apparently spontaneously by the following morning.
Clearly it is worth bearing in mind that priapism may have a variety of causes, general and local. And though sometimes the cause may elude exact diagnosis the patient needs to be investigated thoroughly before treatment is begun.

\section{Familial Dysautonomia}

First recognized as a distinct disease in $1949,,^{1}$ familial dysautonomia has been reported in many patients since. A single case ${ }^{2}$ and two affected sibs ${ }^{3}$ are known from Britain. Inheritance is of the recessive kind, and C. M. Riley ${ }^{4}$ suggested that the defect is a dysfunction of the autonomic nervous system. This causes diminished lacrimation (the most constant sign), instability of temperature, blotching of skin, and excessive sweating. Other features are corneal insensitivity, indifference to pain, reduced tendon reflexes, muscular incoordination, chronic lung disease, and emotional lability. The disease appears to be relatively frequent in Jews.

The recessive inheritance suggested that an enzyme defect is responsible for the autonomic dysfunction, and last year A. A. Smith and his colleagues ${ }^{5}$ provided evidence of a defect in catechol metabolism. The excretion of homovanillic acid, a product of dopamine metabolism, was found to be increased in the urine of patients with familial dysautonomia, while the excretion of vanillylmandelic acid, a product of epinephrine and norepinephrine, was decreased. This suggested a metabolic block in the pathway from catechol precursors to epinephrine and norepinephrine. Smith and J. Dancis ${ }^{6}$ further showed that placing a drop of $2.5 \%$ methacholine into the conjunctival sac of patients with the disease resulted in constriction of the pupil, and that an intradermal injection of histamine produced a weal without the usual axon flare.

A. I. Geltzer and his colleagues ${ }^{7}$ now report from New Haven the tentative diagnosis of familial dysautonomia in a baby only 24 hours old, a diagnosis the more praiseworthy because there was no affected elder sib. The baby showed incoordination of feeding and swallowing, poor muscle tone and absent Moro reflex, lack of response to painful and other stimuli, and recurrent vasomotor attacks lasting about 10 minutes. Other signs consisted in skin mottling, acute respiratory distress, distended abdomen, and opisthotonic posture, followed by a period of pallor and unresponsiveness. The absence of tears does not help at this age because normal babies do not lacrimate until about 8 weeks old. At two weeks of age the diagnosis was confirmed by the intradermal histamine tests and at three weeks of age by the level of homovanillic and vanillylmandelic acids in the urine.

Much work remains to be done to establish the exact chemical defect, and to explain in detail the physiological effects of this defect. But it is now very probable that familial dysautonomia is yet another of the inborn metabolic errors determined by a recessive mutant gene.

\footnotetext{
${ }^{1}$ Riley, C. M., Day, R. L., Greeley, D. McL., and Langford, W. S. Pediatrics, 1949, 3, 468.

${ }^{2}$ McKendrick, T., Arch. Dis. Childh., 1958, 33, 465.

${ }^{3}$ Hutchison, J. H., and Hamilton, W., Lancet, 1962, 1, 1216.

${ }^{4}$ Riley, C. M., Advanc. Pediat., 1957, 9, 157.

${ }^{5}$ Smith, A. A., Taylor, T. and Wortis, S. B., New Engl. F. Med., 1963, 268, 705.

- Smith, A. A., and Dancis, J., F. Pediat., 1963, 63, 838. ' Geltzer, A. I., Gluck, L., Talner, N. S., and Polesky, H. F., New Engl. J.
Med., 1964, 271, 436.
} 